\title{
Cordycepin induces apoptosis in human pancreatic cancer cells via the mitochondrial- mediated intrinsic pathway and suppresses tumor growth in vivo
}

This article was published in the following Dove Press journal: OncoTargets and Therapy

\author{
Yu Zhang, $1,2, *$ Xiao Xi \\ Zhang, ${ }^{3, *}$ Rui Yan Yuan, $1,4, *$ \\ Tai Ren, ${ }^{1,4} \mathrm{Zi}$ Yu Shao, ${ }^{1,4}$ \\ Hong Fei Wang, ${ }^{1,4}$ Wei Long \\ Cai, ${ }^{5} \mathrm{Li}$ Tian Chen, ${ }^{1,4}$ Xu An \\ Wang, ${ }^{4}$ Ping Wang ${ }^{2}$ \\ 'Shanghai Key Laboratory of Biliary \\ Tract Disease Research, Xinhua \\ Hospital, Affiliated to Shanghai Jiaotong \\ University School of Medicine, Shanghai \\ 200092, People's Republic of China; \\ ${ }^{2}$ Department of General Surgery, \\ Hangzhou First People's Hospital, \\ Hangzhou 310006, People's Republic of \\ China; ${ }^{3}$ Shanghai Health Development \\ Research Center, Shanghai 200040, \\ People's Republic of China; \\ ${ }^{4}$ Department of General Surgery and \\ Laboratory of General Surgery, Xinhua \\ Hospital, Affiliated to Shanghai Jiaotong \\ University School of Medicine, Shanghai \\ 200092, People's Republic of China; \\ ${ }^{5}$ Department of General Surgery, \\ Huzhou Central Hospital, Zhejiang \\ 313000, People's Republic of China \\ *These authors contributed equally \\ to this work
}

Correspondence: Li Tian Chen

Department of General Surgery, Xinhua Hospital, Affiliated to Shanghai Jiaotong University School of Medicine, Shanghai 200092, People's Republic of China

Tel +862507 7904

Email chenlitian@xinhuamed.com.cn

Xu An Wang

Department of General Surgery, Xinhua Hospital, Affiliated to Shanghai Jiaotong University School of Medicine, Shanghai 200092, People's Republic of China

Tel +862507 88I3

Email wangxuan@xinhuamed.com.cn

\begin{abstract}
Background: Cordycepin, the main active ingredient of a traditional Chinese herbal remedy extracted from Cordyceps sinensis - has been demonstrated as a very effective anti-inflammatory and antitumor drug. The present study investigated its antitumor effect on pancreatic cancer, a highly aggressive cancer with extremely poor prognosis due to malignancy, and clarified its underlying mechanism both in vitro and in vivo.
\end{abstract}

Methods: The antitumor viability of cordycepin on human pancreatic cancer MIAPaCa-2 and Capan-1 cells was determined by colony formation assays. Annexin V/PI double staining and flow cytometry assay were used to investigate whether cordycepin induced apoptosis and cell cycle arrest. The mitochondrial membrane potential $(\Delta \Psi \mathrm{m})$ was analyzed by Rhodamine 123 staining, and expression of related proteins evaluated by Western blot and immunohistochemistry, both on pancreatic cancer cells and tumor xenografts to reveal the potential mechanism for the effect of cordycepin. Furthermore, the in vivo efficacy was examined on nude mice bearing MIAPaCa- 2 cell tumors treated by intraperitoneal injection of cordycepin $(0,15$, and $50 \mathrm{mg} / \mathrm{kg} / \mathrm{d})$ for 28 days.

Results: Cordycepin inhibited cell viability, proliferation and colony formation ability and induced cell cycle arrest and early apoptosis of human pancreatic cancer cells (MIAPaCa-2 and Capan-1) in a dose- and time-dependent manner. The same effect was also observed in vivo. Decrease of $\Delta \Psi \mathrm{m}$ and upregulation of Bax, cleaved caspase-3, cleaved caspase-9, and cleaved PARP as well as downregulation of Bcl-2 both in vitro and in vivo indicated that the mitochondria-mediated intrinsic pathway was involved in cordycepin's antitumor effect.

Conclusion: Our data showed that cordycepin inhibited the activity of pancreatic cancer both in vitro and in vivo by regulating apoptosis-related protein expression through the mitochondrial pathway and suggest that cordycepin may be a promising therapeutic option for pancreatic cancer.

Keywords: cordycepin, pancreatic cancer, proliferation, apoptosis, mitochondrial pathway

\section{Introduction}

Pancreatic cancer is characterized as a lethal cancer because of difficulties in early diagnosis and a lack of treatment. It is one of the most common causes of cancer death worldwide; the median survival is 5-8 months, and 5-year overall survival rate remains $<5 \%$ when all stages are combined. Meanwhile, the incidence has continued rising over the last 2 decades. ${ }^{1,2}$ Surgical resection with macroscopic tumor clearance still constitutes the cornerstone of potentially curative therapy, but is applicable only in approximately $15 \%-20 \%$ of patients at the time of initial diagnosis. Most patients are 
diagnosed with either metastatic or locally advanced disease, which is not amenable to surgery. ${ }^{3,4}$ The major treatment for these patients is gemcitabine-based combination chemotherapy (gemcitabine combined with nab-paclitaxel, gemcitabine combined with fluorouracil, or gemcitabine combined with erlotinib, etc) or FOLFIRINOX chemotherapy. ${ }^{5,6}$ But none of these regimens prolong the prognosis significantly. Thus, it is necessary to develop new effective treatments and drugs to improve the outcome of unresectable pancreatic cancer.

Cordycepin, also termed 3 '-deoxyadenosine, a derivative of the nucleoside adenosine only differing from the latter by the lack of oxygen in the $3^{\prime}$ position of the ribose entity, is the main active constituent of the traditional Chinese medicine herbs Cordyceps sinensis and Cordyceps militaris. These two fungi have been extensively used as food, medicine, and also in tonics, soups, teas, and herbal formulas to promote health and longevity in old Chinese medical books from ancient times, and they are also used in Tibetan medicine. ${ }^{7-9}$ Numerous notable biological and pharmacological properties have been reported for cordycepin, such as antimicrobial, antifungal, antioxidative, immunomodulation, neuroprotective, antithrombotic, antiadipogenetic effects, etc. ${ }^{10-13}$ Most importantly, cordycepin was found to possess antitumorigenic activity and prolongs survival of tumor-bearing mice, as was observed in mice with liver, gallbladder, renal, lung, and colonic cancer. ${ }^{9,14-18}$ However, the effect on pancreatic cancer cells and the mechanism of action have not been previously investigated. In this study, we found that cordycepin has a strong anticancer effect on pancreatic cancer through the mitochondrial-mediated apoptotic pathway both in vivo and in vitro.

\section{Materials and methods Drugs and antibodies}

Cordycepin was obtained from the National Institute for the Control of Pharmaceutical and Biological Products (Beijing, People's Republic of China). The primary and secondary antibodies used for Western blotting, such as rabbit anti-Bcl-2, anti-Bax, anti-cleaved-caspase-3, anti-cleavedcaspase-9, anti-cleaved PARP, anti-Cdk-2, anti-Cyclin A, and mouse anti- $\beta$-actin, were purchased from Cell Signaling Technology (Beverly, MA, USA).

\section{Cell lines and culture}

Human pancreatic cancer cell lines MIAPaCa-2 and Capan-1 were both purchased from Shanghai Institute of Cell Biology, Chinese Academy of Sciences (Shanghai, People's Republic of China). MIAPaCa-2 was cultured in high-glucose Dulbecco's
Modified Eagle's Medium (Gibco, Grand Island, NY, USA) supplemented with $100 \mathrm{U} / \mathrm{mL}$ penicillin-streptomycin (Hyclone, Logan, UT, USA) and 10\% fetal bovine serum (Gibco). Capan-1 cells were cultured in 1640 medium (Gibco) supplemented with $100 \mathrm{U} / \mathrm{mL}$ penicillin-streptomycin and $10 \%$ fetal bovine serum. Both of the cell lines were maintained in an incubator at $37^{\circ} \mathrm{C}$ with $5 \% \mathrm{CO}_{2}$.

\section{Cell proliferation assay}

MIAPaCa-2 and Capan-1 cells were seeded into 96-well plates at a density of $4 \times 10^{3}$ cells/well, incubated overnight, then treated with various concentrations of cordycepin $(0,50$, $100,200,400,600 \mu \mathrm{g} / \mathrm{mL}$ for both MIAPaCa-2 and Capan-1 cells). Cell viability was quantified using a Cell Counting Kit-8 (CCK-8, Dojindo, Kumamoto, Japan) at 24, 48, and $72 \mathrm{~h}$ after culturing with cordycepin. The absorbance of the solution at $450 \mathrm{~nm}$ was measured with a microplate reader (Quant Bio-Tek Instruments, Winooski, VT, USA).

\section{Colony formation assay}

MIAPaCa-2 and Capan-1 cells in logarithmic growth phase were digested into a single-cell suspension (200 cells $/ \mathrm{mL}$ ) with a trypsin-EDTA (Gibco) solution, then $2 \mathrm{~mL}$ of the suspension was seeded into six-well culture plates (Corning, Corning, NY, USA). After adherence for $10 \mathrm{~h}$, cells were treated with cordycepin $(0,100,200$, and $400 \mu \mathrm{g} / \mathrm{mL}$ for both MIAPaCa- 2 cells and Capan- 1 cells) for $48 \mathrm{~h}$. Then the cordycepin-containing medium was removed and replaced with fresh medium and the cells were allowed to form colonies for 14 days. On day 15, the cells were fixed with $4 \%$ paraformaldehyde for $15 \mathrm{~min}$ and stained with $0.1 \%$ crystal violet (Sigma-Aldrich, St Louis, MO, USA) for $30 \mathrm{~min}$. The plates were air-dried after washing, and stained colonies were photographed using a microscope (Leica, Wetzlar, Germany). The total number of colonies ( $>50$ cells/colony) was counted manually.

\section{Cell apoptosis assay}

The Annexin V/PI assay was performed according to the manufacturer's instructions (Thermo Fisher Scientific, Waltham, MA, USA) to analyze apoptosis. MIAPaCa-2 and Capan-1 cells were seeded into 6-well plates with $1 \times 10^{6}$ cells/well and treated with cordycepin $(0,100,200$, and $400 \mu \mathrm{g} / \mathrm{mL}$ for both MIAPaCa-2 and Capan-1 cells). After $48 \mathrm{~h}$, the cells were collected and washed with cold PBS twice, then centrifuged and resuspended at a density of $1 \times 10^{6}$ cells $/ \mathrm{mL}$ in $100 \mu \mathrm{L}$ of binding buffer containing $5 \mu \mathrm{L}$ of Annexin V-FITC and $1 \mu \mathrm{L}$ of PI working solution 
$(100 \mu \mathrm{g} / \mathrm{mL})$. After incubation at room temperature for 15 min in the dark, $400 \mu \mathrm{L}$ of binding buffer was added to each sample. The stained cells were analyzed by flow cytometry (BD Biosciences, San Diego, CA, USA) for at least 10,000 events. Cell population in different quadrants was measured by quadrant statistics.

\section{Mitochondrial membrane potential $(\Delta \Psi \mathrm{m})$ assay}

After treatment with different concentrations of cordycepin $(0,100,200$, and $400 \mu \mathrm{g} / \mathrm{mL}$ for both MIAPaCa-2 and Capan-1 cells) for $48 \mathrm{~h}$, the cells were collected and washed twice with cold PBS, followed by incubation with Rhodamine 123 (Sigma-Aldrich) at $37^{\circ} \mathrm{C}$ for $30 \mathrm{~min}$ in the dark. Subsequently, the cells were washed twice with cold PBS and the $\Delta \Psi \mathrm{m}$ was analyzed by flow cytometry.

\section{Cell cycle analysis}

MIAPaCa-2 and Capan-1 cells were seeded into a 6-well culture plate, then treated with various concentrations of cordycepin $(0,100,200$, and $400 \mu \mathrm{g} / \mathrm{mL}$ for both strains of cells) for $48 \mathrm{~h}$. Both floating and adherent cells were collected and washed twice with PBS. After fixation in cold $70 \%$ ethanol at $4^{\circ} \mathrm{C}$ overnight, the cells were incubated with $10 \mathrm{mg} / \mathrm{mL}$ RNase and $1 \mathrm{mg} / \mathrm{mL}$ PI (Sigma-Aldrich) at room temperature for $30 \mathrm{~min}$ in the dark. The samples were analyzed with a flow cytometer, and the percentage of cells in the $\mathrm{G} 0 / \mathrm{G} 1, \mathrm{~S}$, and $\mathrm{G} 2 / \mathrm{M}$ phases were determined using Cell Quest acquisition software (BD Biosciences).

\section{Western blot analysis}

For MIAPaCa-2 and Capan-1 cells, after treatment with cordycepin $(0,100,200$, and $400 \mu \mathrm{g} / \mathrm{mL}$ for both strains of cells) for $48 \mathrm{~h}$, the cells were washed in PBS and lysed in RIPA buffer (Beyotime, Shanghai, People's Republic of China) supplemented with protease inhibitor (Roche Applied Science, Indianapolis, IN, USA). For the tumor tissue, the tissue was dissected into around $5 \mathrm{mg}$ pieces, then disrupted in liquid nitrogen and lysed in RIPA buffer to extract protein. The total protein concentration was determined using the BCA assay (Beyotime) with BSA as a standard. Equal amounts of protein from each sample were loaded in the lane for SDS-PAGE and transferred to polyvinylidene difluoride membranes (Millipore, Bedford, MA, USA). Then, membranes were blocked with $5 \%$ skim milk for $1 \mathrm{~h}$ at room temperature and then incubated with different primary antibodies and mouse anti- $\beta$-actin at $4^{\circ} \mathrm{C}$ overnight, followed by incubation with a horseradish peroxidase-conjugated goat anti-rabbit/anti-mouse secondary antibody (1:5,000; Abcam, Cambridge, UK). The bands were scanned and quantified using the Gel Doc 2000 (BioRad, Hercules, CA, USA).

\section{In vivo efficacy of cordycepin}

Six- to eight-week-old BALB/c homozygous (nu/nu) nude mice (18-20 g body weight) were purchased from Shanghai SLAC Laboratory Animal Co., Ltd. (Shanghai, People's Republic of China). The mice were maintained in a specific pathogen-free environment. All procedures were approved and carried out in accordance with the Institutional Animal Care and Use Committee of Shanghai Jiao Tong University (Shanghai, People's Republic of China). The investigation conforms with the Guide for the Care and Use of Laboratory Animals published by the US National Institute of Health (NIH Publication No 85-23, revised 1996). MIAPaCa-2 cells in log-phase growth were resuspended in $100 \mu \mathrm{L}$ PBS and then injected into the left axilla of nude mice $\left(10^{5} / \mathrm{mice}\right)$. On Day 5, these mice were randomly divided into 3 groups (5 mice/group). The control group received an intraperitoneally (IP) injection of medium each day. The other 2 groups were administered an IP injection of cordycepin (15 and $50 \mathrm{mg} / \mathrm{kg}$ every day). On Day 28, all nude mice were sacrificed, and the tumor tissue was removed and weighed. Then, the tumor tissue was cut into suitable pieces for Western blot analysis and immunohistochemistry (IHC).

\section{IHC staining for caspase-3 in xenograft tumor}

Tumors were removed from the 3 groups and formalin-fixed and paraffin-embedded. The tumor blocks were serially sectioned on a cryostat (Leica Microsystems, Wetzlar, Germany) with section thickness ranging from 3 to $4 \mu \mathrm{m}$. The tissue sections were deparaffinized in xylene twice ( 5 min for each xylene solution) and rehydrated using descending alcohol gradient $(100 \%, 95 \%, 85 \%, 80 \%$, and $75 \%)$. Endogenous peroxidase and protein were blocked in a peroxidase blocking solution $(0.03 \%$ hydrogen peroxide containing phosphate) for 5 min after the antigen retrieval process. This was followed by incubation in blocking buffer (containing goat serum) and then primary caspase-3 (Biogenex, Fremont, CA, USA) antibodies were added and incubated overnight at $4{ }^{\circ} \mathrm{C}$. The sections were then incubated in secondary antibodies (Sino Biological, Beijing, People's Republic of China) following PBS washes. Sections were mounted with DPX mounting solution (BDH Associates Inc., Atlanta, GA, USA), observed, and photographed under light microscope. The presence of 
brown color, regardless of staining intensity, was regarded as expression of caspase-3.

\section{Statistical analysis}

Statistical analyses were conducted using SPSS 19.0 software (IBM Corporation, Armonk, NY, USA). All data points represent the mean of triplicate independent data points, and all quantified data are expressed as the mean \pm SD. Statistical significance was calculated using the Student's $t$-test, and $p$-values of $<0.05(* p<0.05, * * p<0.01, * * * p<0.001)$ were considered statistically significant for all tests.

\section{Results}

\section{Cordycepin inhibits the proliferation of pancreatic cancer cells}

To evaluate the antitumor viability of cordycepin on human pancreatic cancer cells, CCK-8 assay and colony formation assay were performed. After treatment with various concentrations $(0,50,100,200,400$, and $600 \mu \mathrm{g} / \mathrm{mL}$ for both MIAPaCa-2 and Capan-1 cells) of cordycepin for 24, 48, and $72 \mathrm{~h}$, the growth curve of CCK- 8 assay results revealed that MIAPaCa-2 and Capan-1 cell viability decreased in a dose- and time-dependent manner as compared with control (Figure $1 \mathrm{~A}$ and $\mathrm{B}$ ). The $\mathrm{IC}_{50}$ (the concentration at which $50 \%$ inhibition of cell growth was achieved) of cordycepin in MIAPaCa- 2 and Capan- 1 cells at $48 \mathrm{~h}$ was approximately 106.0 and $108.1 \mu \mathrm{g} / \mathrm{mL}$, respectively. This was consistent with the data of the colony formation assay; the colony count confirmed that cordycepin suppressed the colony formation ability significantly in both cell lines in a dose-dependent manner (Figure 1C-F).

These findings suggest that cordycepin exerts a significant antiproliferation effect on pancreatic cancer in vitro and warranted further investigation.

\section{Cordycepin induces apoptosis in pancreatic cancer cells}

To investigate the reason for cordycepin-mediated cell proliferation inhibition, Annexin V-FITC/PI double staining and flow cytometry were conducted. As show in Figure 2, the percentage of early apoptotic cells in MIAPaCa- 2 and Capan-1 populations treated with $400 \mu \mathrm{g} / \mathrm{mL}$ cordycepin was $66.1 \% \pm 3.40 \%$ and $74.7 \% \pm 2.38 \%$, respectively, compared to the percentage of early apoptotic cells in the negative control $(28.1 \% \pm 2.70 \%$ for MIAPaCa- 2 and $23.4 \% \pm 1.62 \%$ for Capan-1 cells). Also, the percentage of cells that survived significantly reduced in a dose-dependent manner. These data indicate that cordycepin induced a dose-dependent increase in both early and late stage apoptosis in MIAPaCa-2 and Capan-1 cells, and especially in early stage.

As can be seen in Figure 2C and D, treatment of Capan-1 cells with cordycepin at $400 \mu \mathrm{g} / \mathrm{mL}$ for $48 \mathrm{~h}$ showed a reduction in late apoptosis. However, in MIAPaCa-2 cells with the same concentration, there was increase in late apoptosis. The reason could be because we used Annexin V/PI assay to perform the apoptosis assay; the Annexin V+/PI+ quadrant indicates late apoptosis, but may also contain some necrotic cells, which may influence the result. To conclude, cordycepin exerted its inhibitory function on cell proliferation in pancreatic cancer by inducing apoptosis, resulting in cell death.

\section{Cordycepin decreases $\Delta \Psi \mathrm{m}$ in pancreatic cancer cells}

After treatment with cordycepin for $48 \mathrm{~h}, \mathrm{MIAPaCa}-2$ and Capan-1 cell lines were examined using Rhodamine 123, a fluorescent stain that marks mitochondria in living cells. As shown in Figure 3, the results showed decrease in the percentage of $\Delta \Psi \mathrm{m}$ from $94.0 \% \pm 3.05 \%$ to $68.9 \% \pm 2.90 \%$, $29.2 \% \pm 4.75 \%$, and $2.7 \% \pm 5.36 \%$ for MIAPaCa-2 cells and from $81.5 \% \pm 6.67 \%$ to $50.2 \% \pm 3.30 \%, 26.1 \% \pm 2.99 \%$, and $6.9 \% \pm 3.10 \%$ for Capan- 1 cells at $0,100,200$, and $400 \mu \mathrm{g} / \mathrm{mL}$ concentrations of cordycepin, respectively. These data indicate that cordycepin promotes apoptosis of pancreatic cancer cells through the mitochondrial-dependent apoptotic pathway.

\section{Cordycepin induced apoptosis via regulation of caspase and $\mathrm{Bcl}-2$ family members}

To further examine the mechanism of apoptosis induced by cordycepin in human pancreatic cancer cells, Western blot analysis was performed to investigate the expression of Bcl-2 family and caspase family proteins. After treatment with cordycepin for $48 \mathrm{~h}$, upregulated cleaved caspase-3, cleaved caspase-9, cleaved PARP, and Bax, and downregulated Bcl-2 were found in both MIAPaCa-2 and Capan-1 cells (Figure 4A and B). In addition, Bcl-2/Bax ratio was calculated to measure the comparative level of the 2 proteins. The results showed a significant decrease of $\mathrm{Bcl}-2 / \mathrm{Bax}$ ratio with a higher dose of cordycepin (Figure 4C and D).

\section{Cordycepin triggers S-phase arrest in pancreatic cancer cells}

To assess whether the effect of cordycepin on the proliferation of pancreatic cancer cells was also mediated by cell cycle progression inhibition, flow cytometry assay was performed. As observed in Figure 5, after treatment with 
A

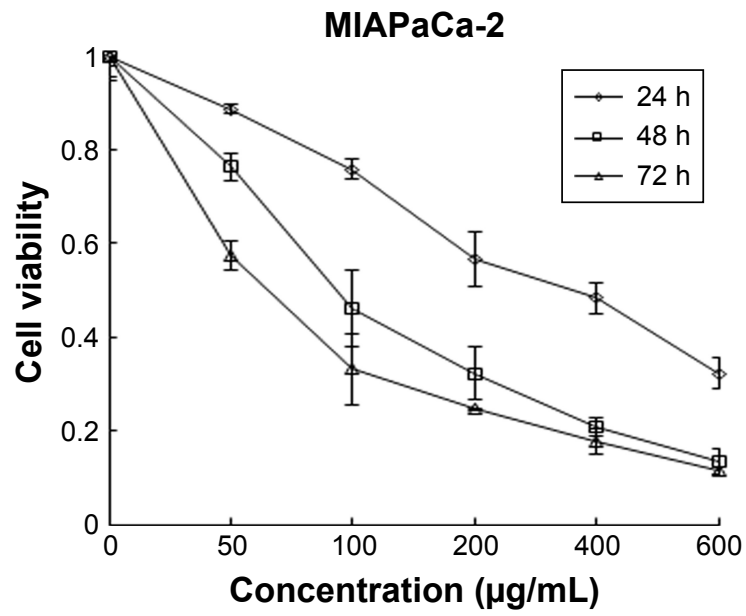

C

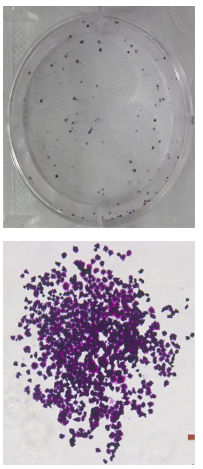

E

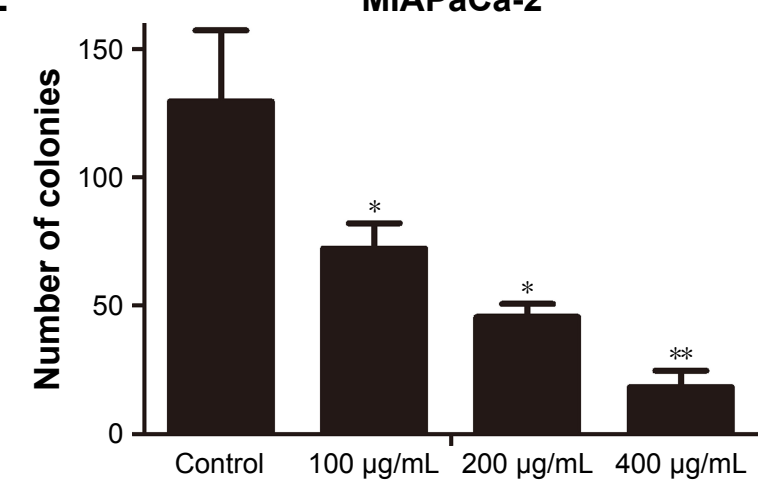

B

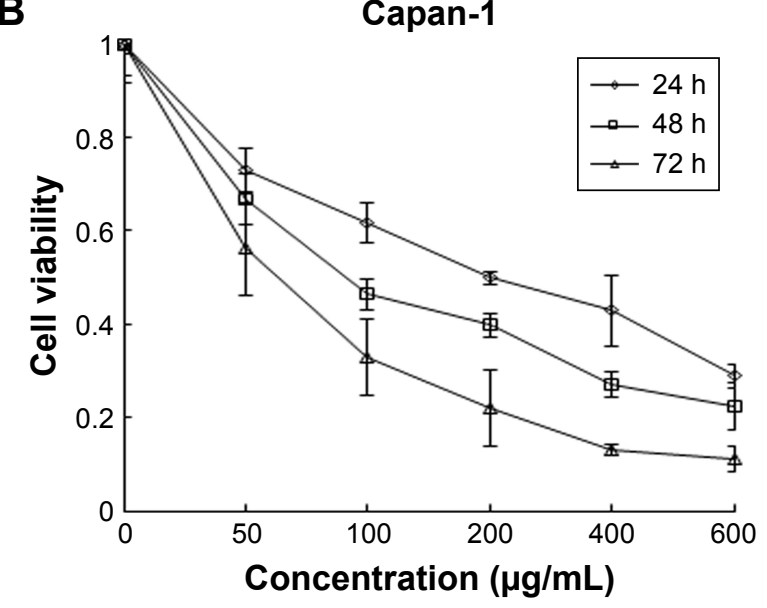

D

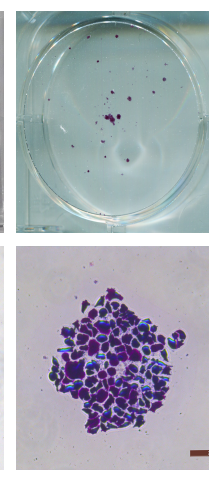

F

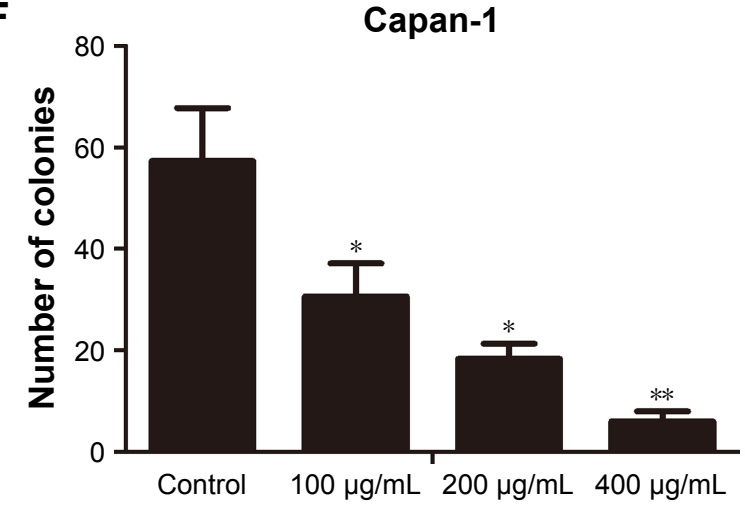

Figure I Cordycepin inhibits the proliferation of pancreatic cancer cells.

Notes: (A, B) MIAPaCa-2 and Capan-I cells were treated with cordycepin (0, 50, 100, 200, 400, and $600 \mu \mathrm{g} / \mathrm{mL}$ ) for 24,48 , and 72 h. Cell viability was determined by CCK-8 assays. (C, D) MIAPaCa-2 and Capan-I cells were treated with various concentrations of cordycepin and cultured in fresh medium for 14 days to form colonies. Pictures were taken after Giemsa staining of the colonies. (E, F) Detailed information on colony formation is shown. Data are presented as mean \pm SD $(n=3)$. ${ }^{*} p<0.0 \mathrm{I}, * * p<0.00 \mathrm{I}$.

Abbreviation: CCK-8, cell counting kit-8.

different concentrations of cordycepin for $48 \mathrm{~h}$, the proportion of cells in each stage changed in a similar pattern. The increasing percentage of cells in S phase indicated S-phase arrest, and a higher dose of cordycepin enhanced this effect. These data illustrated that cordycepin induces S-phase arrest in pancreatic cancer cells in a dose-dependent manner.

To further investigate the mechanism of cordycepin-induced cell cycle arrest, the expression of cell cycle regulatory proteins was examined by Western blot assay. The result showed a strong downregulation of cyclin A and Cdk-2 in cordycepintreated MIAPaCa-2 and Capan-1 cell lines (Figure 5E and F), which means that cordycepin induces S-phase arrest through downregulation of the expression of cell cycle proteins.

\section{Cordycepin inhibits the growth of MIAPaCa-2 xenografts in nude mice}

To investigate whether the tumor suppression ability of cordycepin is the same in vivo, vehicle (1640 medium) or 
A

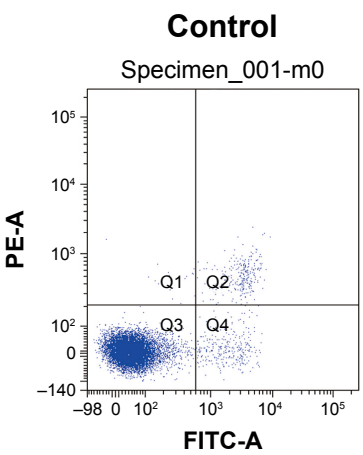

B

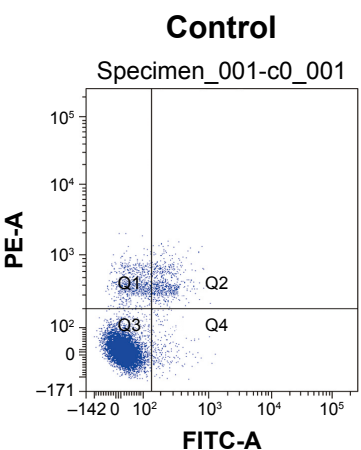

MIAPaCa-2

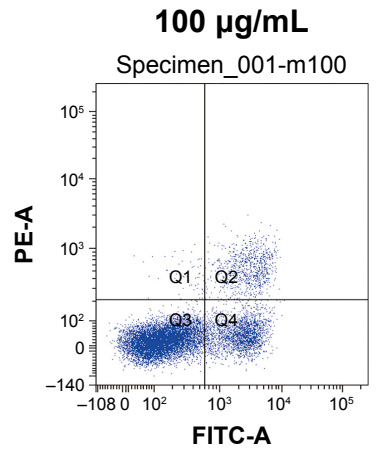

$200 \mu \mathrm{g} / \mathrm{mL}$

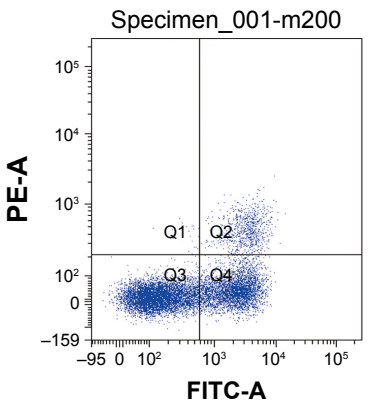

$400 \mu \mathrm{g} / \mathrm{mL}$

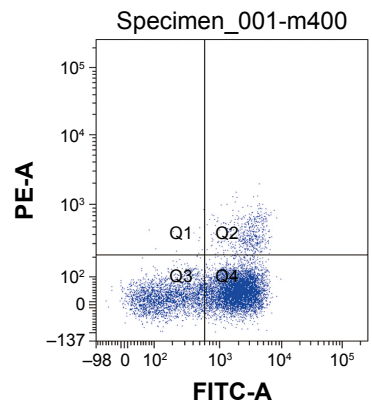

Capan-1
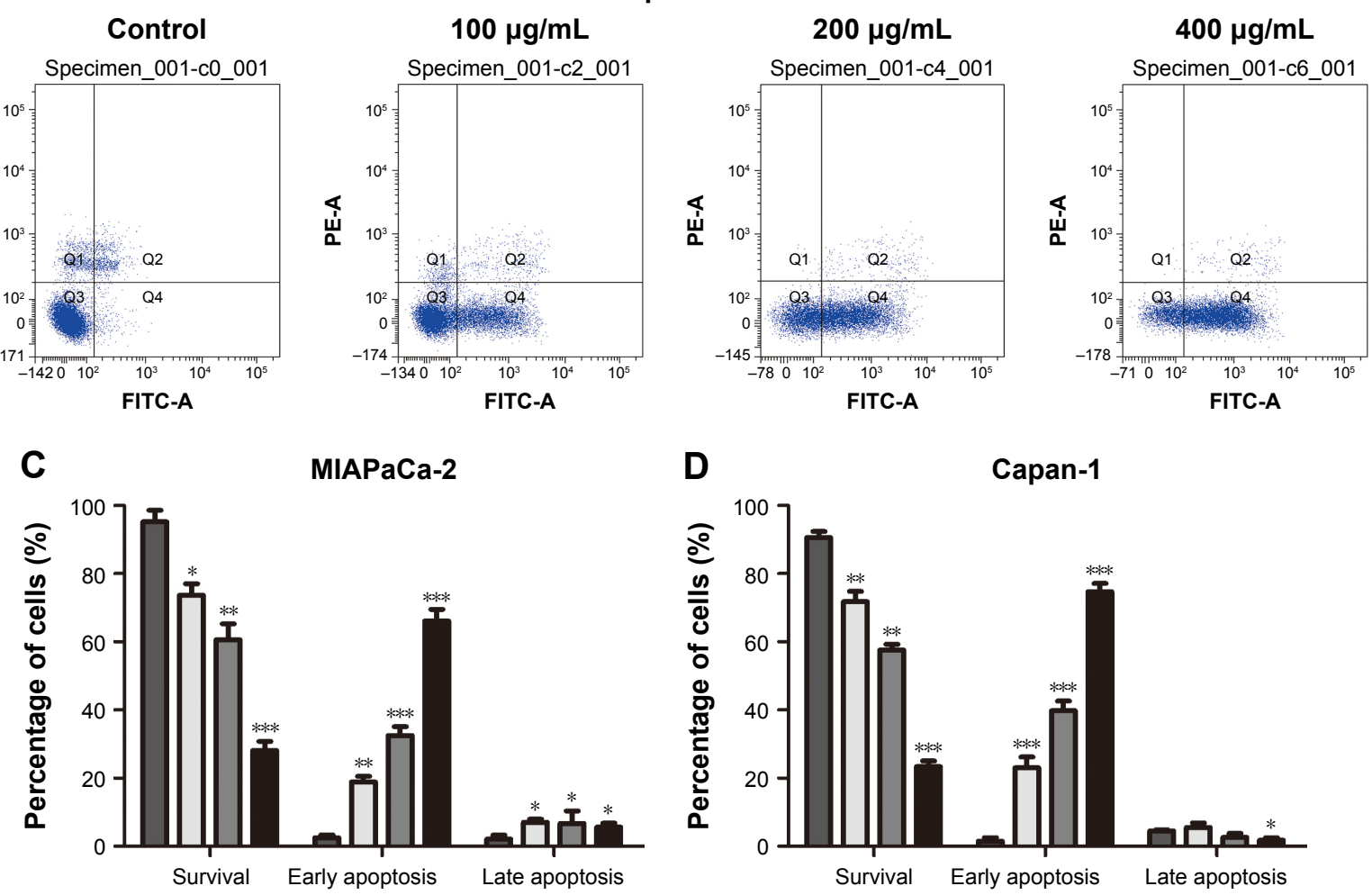

D

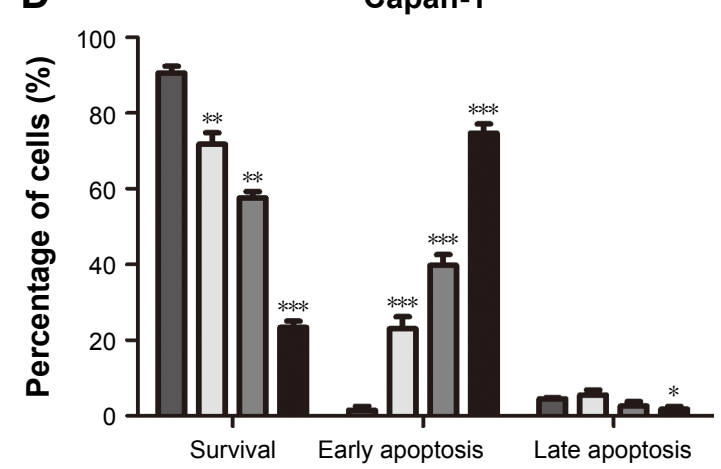

Control

$100 \mu \mathrm{g} / \mathrm{mL}$

$200 \mu \mathrm{g} / \mathrm{mL}$

$400 \mu \mathrm{g} / \mathrm{mL}$

Figure 2 Cordycepin induces apoptosis in pancreatic cancer cells.

Notes: (A, B) MIAPaCa-2 and Capan-I cells were incubated with cordycepin (0, 100, 200, and $400 \mu \mathrm{g} / \mathrm{mL})$ for $48 \mathrm{~h}$, then stained with Annexin V/PI and analyzed by flow cytometry. The Q3 quadrant (Annexin V-/PI-), Q4 quadrant (Annexin V+/PI-), and Q2 quadrant (Annexin V+/PI+) represent the group of normal cells, early apoptotic cells, and late apoptotic cells, respectively. (C, D) The percentage of cells in each stage is presented. Data are presented as mean \pm SD $(n=3)$. ${ }^{*} p<0.05$, $* * p<0.0$ I, $* * * p<0.00$ I.

cordycepin (15 and $50 \mathrm{mg} / \mathrm{kg}$ daily by IP injection) was administered to the nude mice bearing MIAPaCa- 2 cell tumors for 28 days. The tumors were removed and weighed; a remarkable decrease in both tumor volume and weight in a dosedependent manner was found after treatment with cordycepin (Figure 6A-C). There was no significant difference in body weight between the 3 groups of mice, indicating that treatment with cordycepin led to no systemic toxicity. The result showed inhibitive ability of cordycepin against tumor growth in vivo.
To confirm our previous conclusion, we also analyzed the expression level of apoptosis-related proteins in xenograft tumors. The tumors removed from the nude mice were excised for Western blot analysis, and the results were in agreement with the results obtained in vitro: dramatic upregulation of cleaved caspase-3, cleaved caspase-9, cleaved PARP, and Bax, and downregulation of Bcl-2 in cordycepintreated tumor tissue (Figure 7A). Moreover, IHC analysis of xenograft tumors revealed remarkably decreased levels 
A

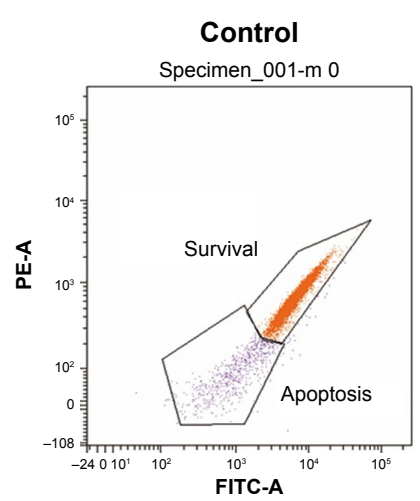

B

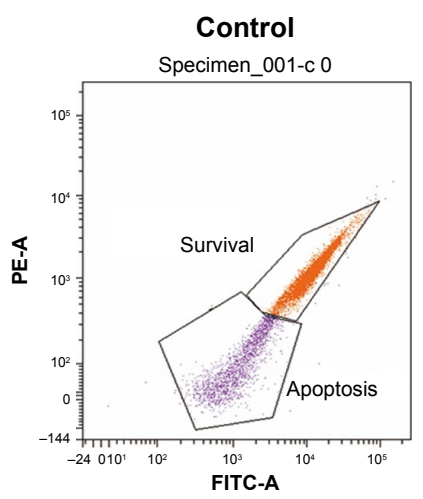

MIAPaCa-2

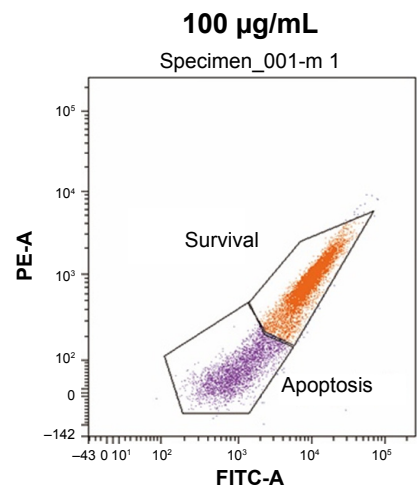

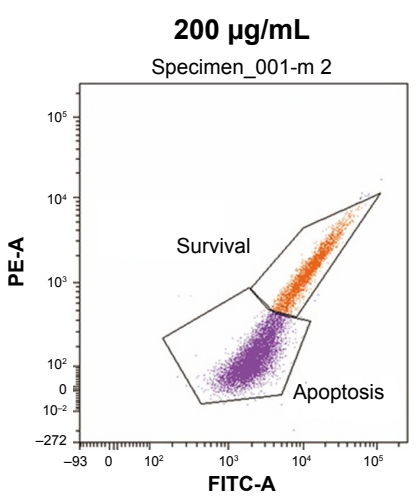

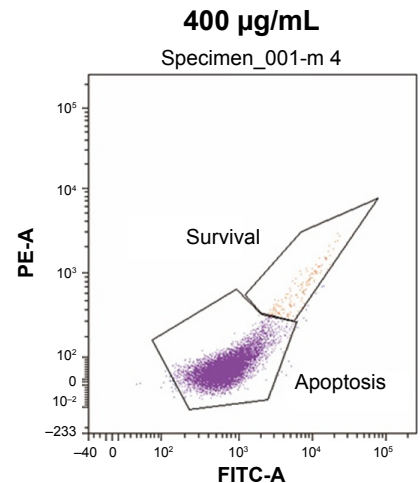

\section{Capan-1}
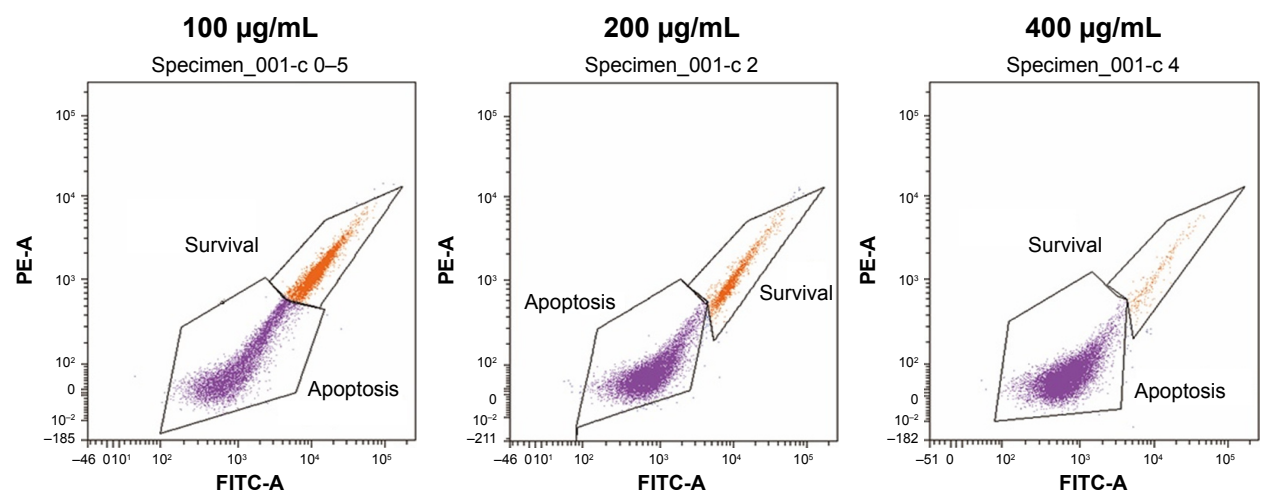

C

MIAPaCa-2

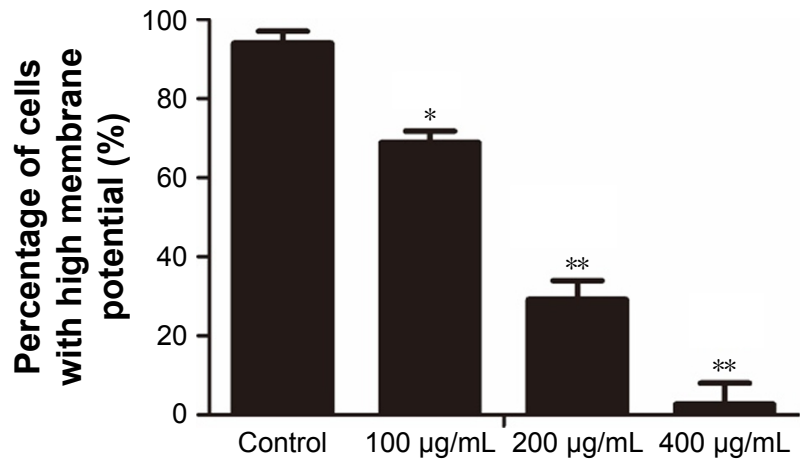

D

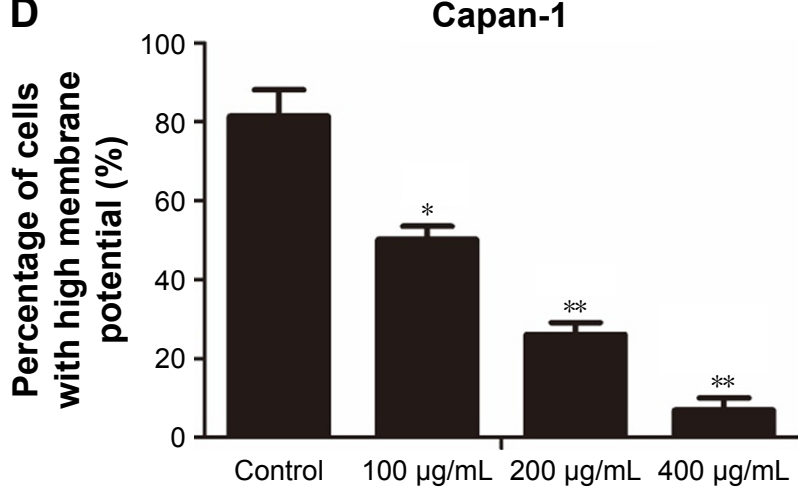

Figure 3 Cordycepin decreases $\Delta \Psi \mathrm{m}$ in pancreatic cancer cells.

Notes: (A, B) MIAPaCa-2 and Capan-I cells were treated with cordycepin (0, 100, 200, $400 \mu \mathrm{g} / \mathrm{mL})$ for $48 \mathrm{~h}$, then flow cytometric analysis of $\Delta \Psi \mathrm{m}$ was performed after Rhodamine 123 staining. "Survival" indicates cells with high $\Delta \Psi \mathrm{m}$, while "apoptosis" indicates low $\Delta \Psi \mathrm{m}$. (C, D) Percentage of cells with high $\Delta \Psi \mathrm{m}$ (survival) and low $\Delta \Psi \mathrm{m}$ (apoptosis) are presented. Data are presented as mean \pm SD $(n=3) . *_{p}<0.0$ I, $*^{*} p<0.00 \mathrm{I}$.

Abbreviation: $\Delta \Psi \mathrm{m}$, mitochondrial membrane potential.

of caspase-3 (not cleaved) in cordycepin-treated tumors compared to control mice (Figure 7B).

\section{Discussion}

In the present study, one of the main active ingredients of a famous traditional Chinese herbal remedy named cordycepin was evaluated to assess whether it possesses anticancer efficacy in pancreatic cancer, a very malignant tumor seen in humans.
First, antiproliferative and antitumor growth effects were evaluated; the results of CCK- 8 and colony formation assays showed the significant proliferation inhibition ability of cordycepin in a time- and dose-dependent manner on MIAPaCa-2 and Capan-1 pancreatic cancer cell lines, which was consistent with the results seen in nude mice carrying MIAPaCa-2 xenografts treated by IP injection of cordycepin. All these data confirmed that cordycepin can inhibit pancreatic cancer. 
A
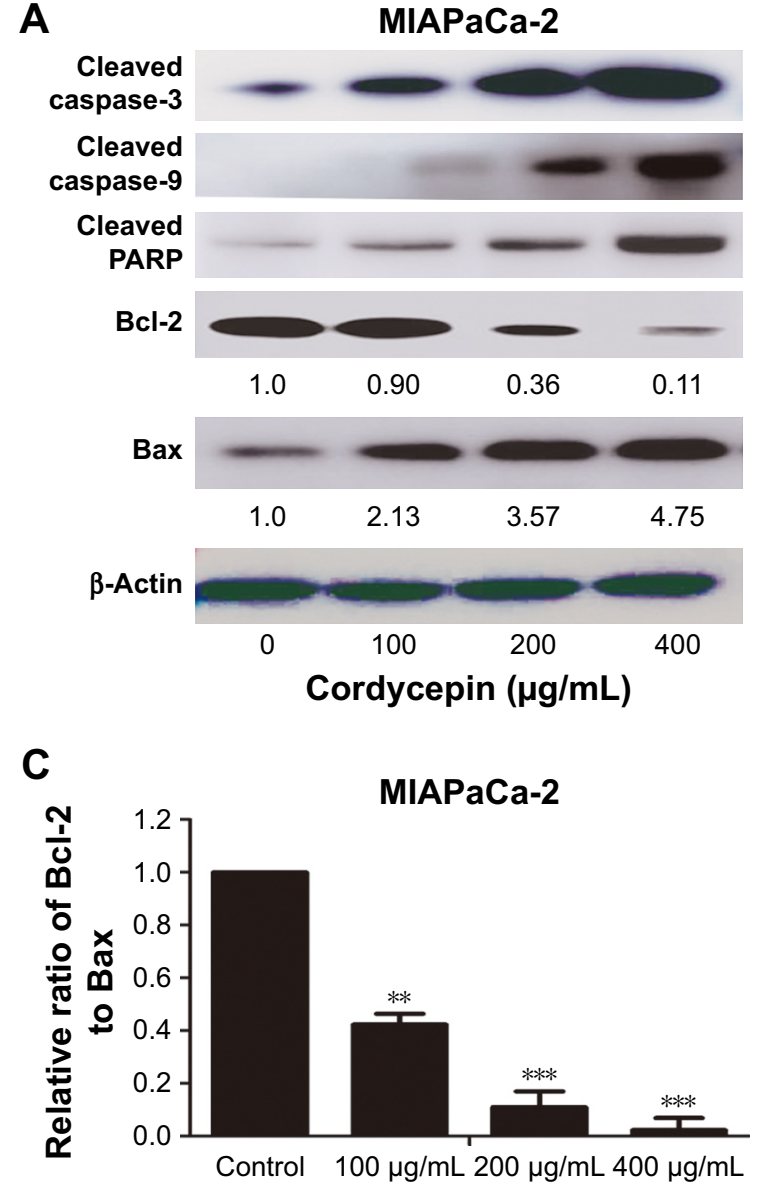

B

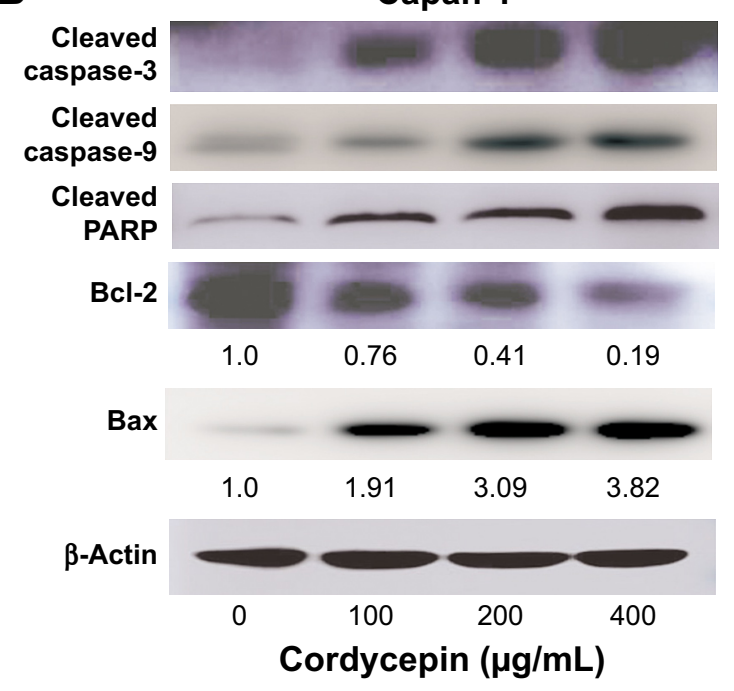

D

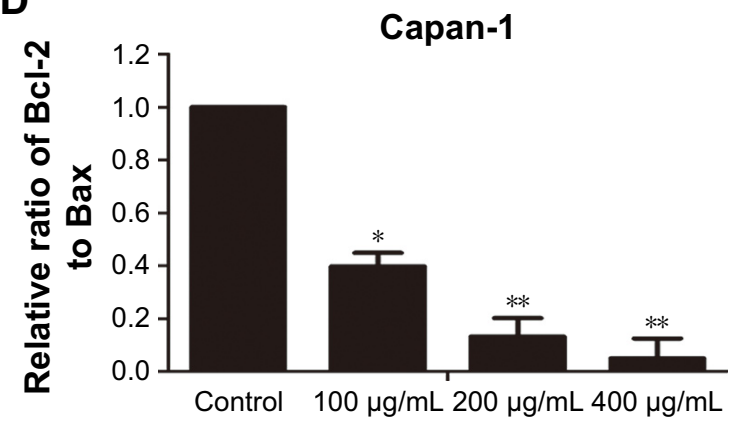

Figure 4 Cordycepin-induced apoptosis via regulation of caspase and Bcl-2 family members in pancreatic cancer cells.

Notes: (A, B) Representative results of Western blot analysis for the protein level of cleaved caspase-3, cleaved caspase-9, cleaved PARP, Bcl-2, and Bax in MIAPaCa-2 and Capan-I cells treated with cordycepin at indicated doses for $48 \mathrm{~h}$. $\beta$-actin was used as a loading control. Band density of Bcl-2 and Bax are presented. (C, D) Ratio of Bcl-2 to Bax determined by band density compared with the control (designated as I.00). Data are presented as mean $\pm S D(n=3)$. $* p<0.05$, *** $p<0.01$, *** $p<0.00$ I.

Apoptosis is the major target for many anticancer drugs to induce the death of cancer cells. Accumulating evidence has shown the effect of cordycepin in the induction of tumor cell apoptosis. ${ }^{15-19}$ To further study the efficacy of cordycepin, an Annexin V-FITC/PI double staining and flow cytometry assay was conducted, and we found the number of early and late apoptotic pancreatic cancer cells was significantly increased, while the percentage of surviving cells dropped dramatically after treatment with cordycepin. Next, we investigated the mechanism of apoptosis induced by cordycepin. As reported earlier, 3 major pathways are involved in the regulation of apoptosis: mitochondria-mediated intrinsic pathway, the death receptor-induced extrinsic pathway, and endoplasmic reticulum stress-mediated apoptotic pathway. ${ }^{20}$ Mitochondrial functions would be damaged on decrease of $\Delta \Psi \mathrm{m}$, thus resulting in cell death. Loss of $\Delta \Psi \mathrm{m}$ is often evidence of apoptosis mediated by the mitochondrial pathway. ${ }^{21}$ In the mitochondrial pathway, Bcl-2 family and caspases play important roles. Bcl-2 family proteins protect the stability of the mitochondrial membrane and modulate the reactions of the mitochondrial-mediated intrinsic apoptotic pathway, ${ }^{22}$ Bcl-2 and Bax are the key regulators of Bcl-2 family. During apoptosis, cytochrome $\mathrm{c}$ is released into cytoplasm through the mitochondrial membrane owing to its increased permeability. Bcl-2 is recognized as an antiapoptotic protein owing to its function of preventing the release of cytochrome c. Bax, on the other hand, is identified as a proapoptotic protein, with the effect of permeabilizing the membrane, thus releasing cytochrome $\mathrm{c}$. The ratio of $\mathrm{Bcl}-2 / \mathrm{Bax}$ reveals the occurrence and severity of apoptosis; a low Bcl-2 to Bax ratio is highly related to $\Delta \Psi \mathrm{m}$ collapse, release of cytochrome c, and subsequent apoptosis. ${ }^{23}$ The caspase family is another essential regulator of apoptosis; initiator caspases such as caspase- 8 and -9 are closely coupled to proapoptotic signals. Once initiator caspases are activated, they produce a chain reaction, cleaving and activating several other downstream executioner caspases such as caspase-3 and -7, 
A

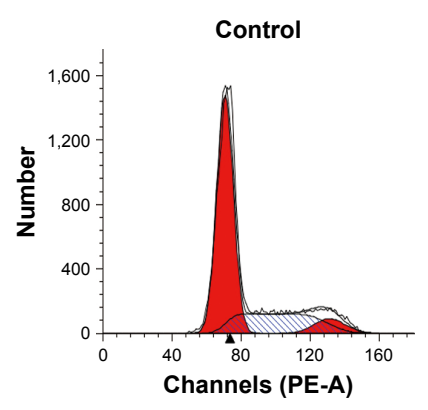

B

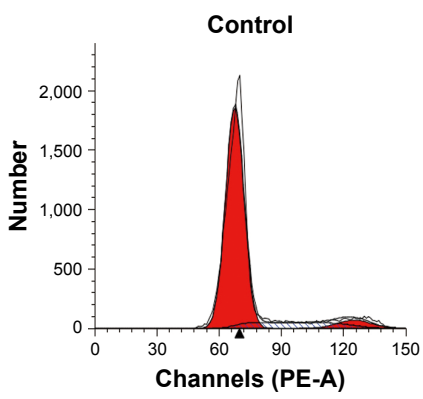

MIAPaCa-2

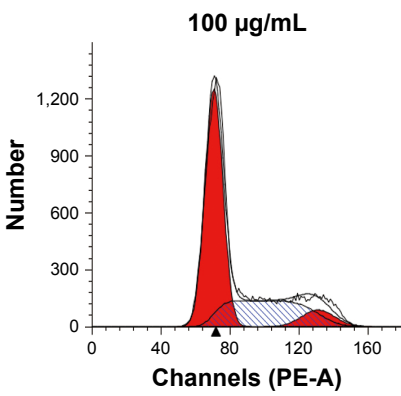

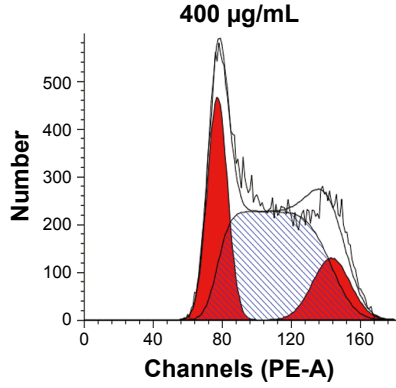

Capan-1

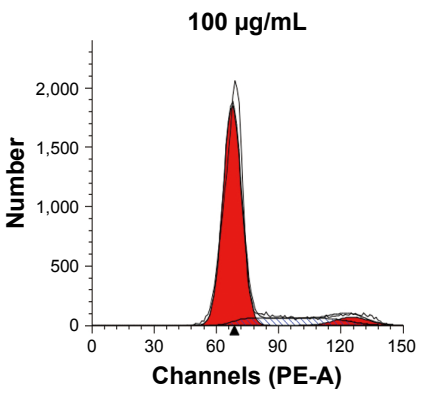

$400 \mu \mathrm{g} / \mathrm{mL}$

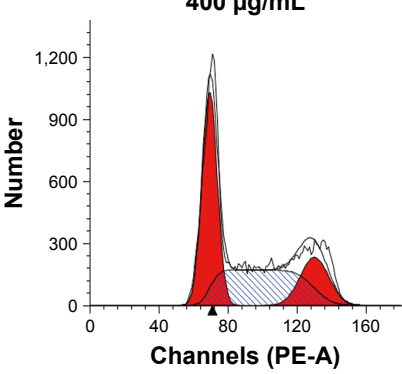

$\square$ Dip G1 $\square$ Dip G2 $\quad$ Dip S

C

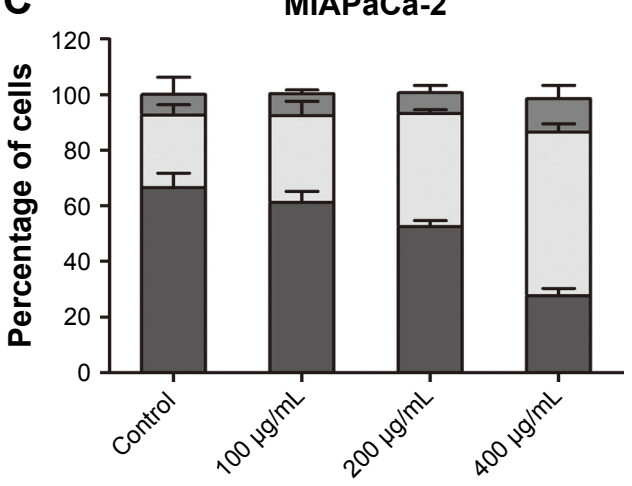

D

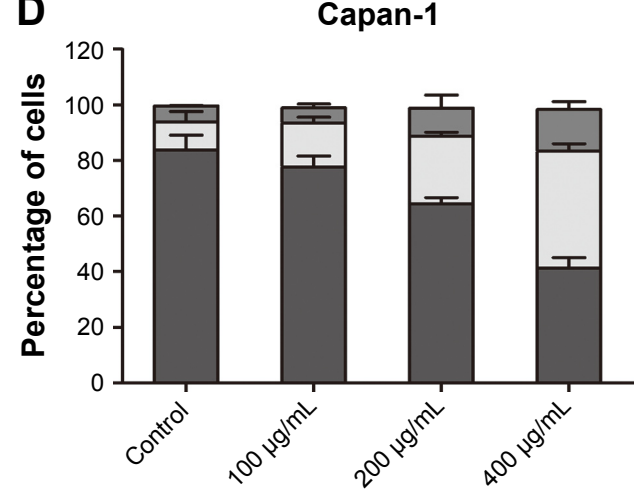

G1 $\square$ s $\square$ G2/M

E

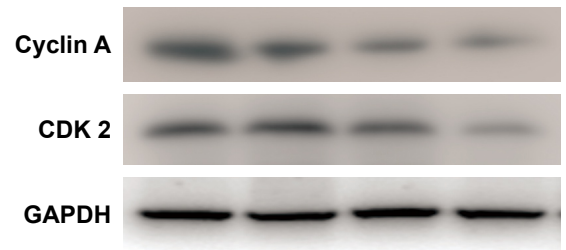

F

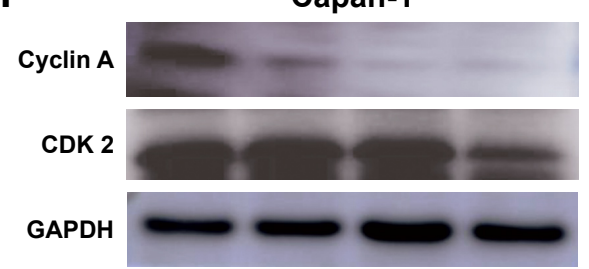

Figure 5 Cordycepin induces S-phase arrest.

Notes: (A, B) MIAPaCa-2 and Capan-I cells were treated with cordycepin (0, 100, 200, $400 \mu \mathrm{g} / \mathrm{mL})$ for $48 \mathrm{~h}$ and the DNA content was analyzed by flow cytometry. (C, D) The percentage of cells in the GI, S, and G2/M phases of the cell cycle are shown. Results are expressed as mean \pm SD from 3 independent experiments. (E, F) Representative results of Western blot analysis for the protein level of cyclin A and Cdk-2 treated with cordycepin at indicated doses for $48 \mathrm{~h}$. GAPDH was used as a loading control.

which in turn lead to apoptosis by cleaving targeted cellular proteins. ${ }^{24,25}$ In a typical mitochondrial pathway, cytochrome $\mathrm{c}$ in the cytoplasm induces the activation of caspase-9, the latter subsequently activates caspase-3, which is responsible for cleaving many substrates in the cell, such as PARP, then resulting in cell death.

Our results demonstrated decrease of $\Delta \Psi \mathrm{m}$ and upregulated cleaved caspase-3, cleaved caspase-9, cleaved PARP, 


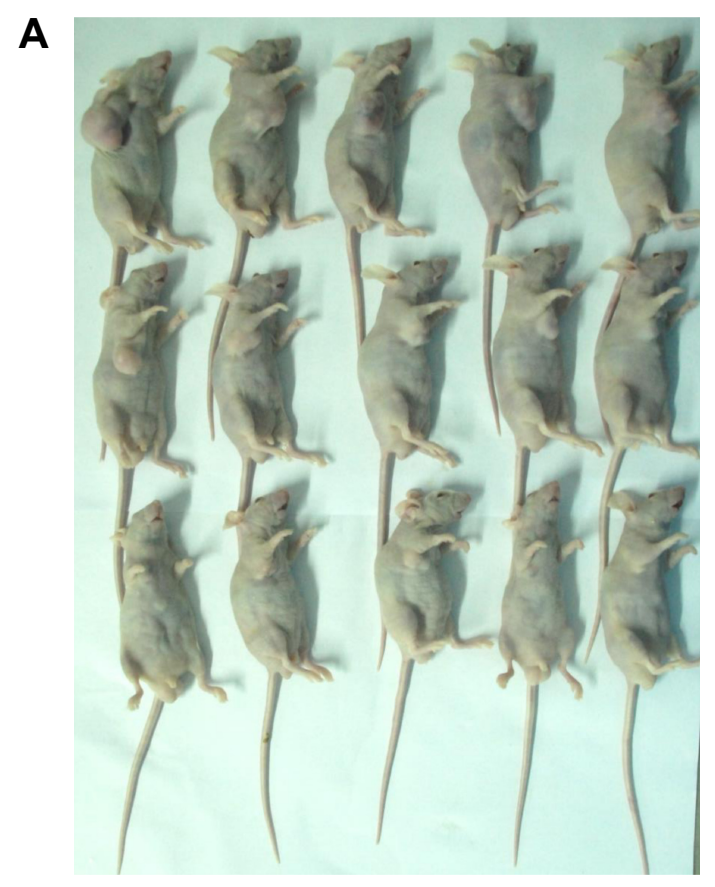

B

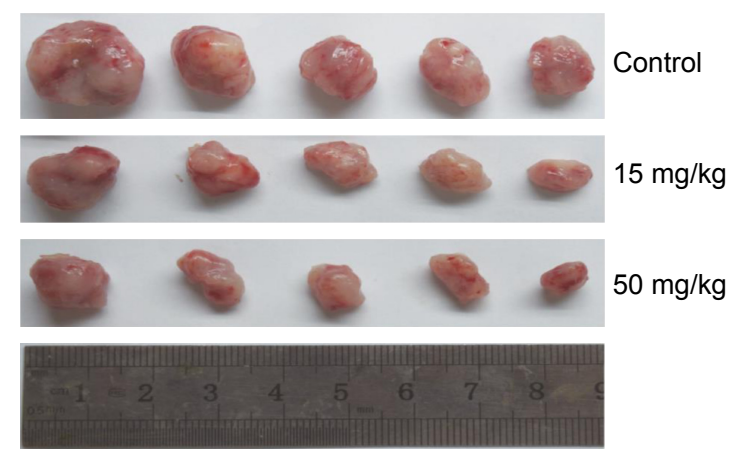

C

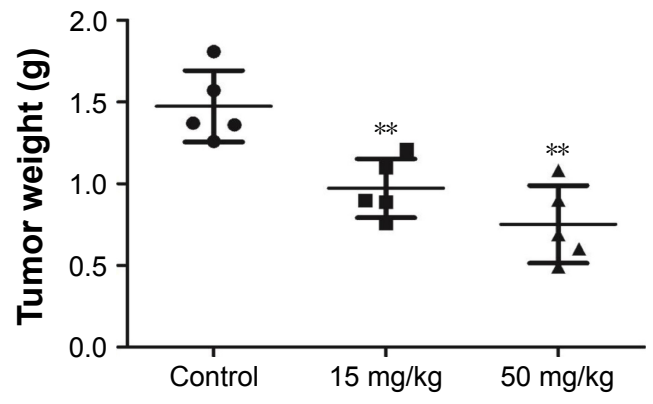

Figure 6 Cordycepin inhibits the proliferation of pancreatic cancer cells in vivo.

Notes: (A, B) Photographs of tumor xenografts 28 days after inoculation. (C) Tumor weight in the cordycepin group at the end of the experiment was significantly lower than that in the control group. Data are presented as mean $\pm S D(n=3) . * * p<0.0$ I.

and Bax, as well as downregulated Bcl-2, both in vitro and in vivo, after treatment with cordycepin. These findings indicate that treatment with cordycepin results in mitochondrial dysfunction in pancreatic cancer cells, which then promotes the release of cytochrome c from mitochondria, which binds Apaf- 1 and recruits an activation complex called the apoptosome with initiator caspase-9. Cleaved caspase-9 then goes on to activate downstream executioner caspase-3, which amplifies the initiating signals of caspase- 9 and causes cleavage of the DNA repair enzyme, PARP, eventually resulting in DNA degradation, thus triggering apoptosis (Figure 8). All these investigations provided strong evidence to support the notion that cordycepin induces apoptosis of pancreatic cancer via the mitochondrial-mediated intrinsic apoptotic pathway.

The effect on cell cycle progression is a significant part of the antitumor function of agents, in addition to effects on cell viability. By performing the flow cytometry assay,
A

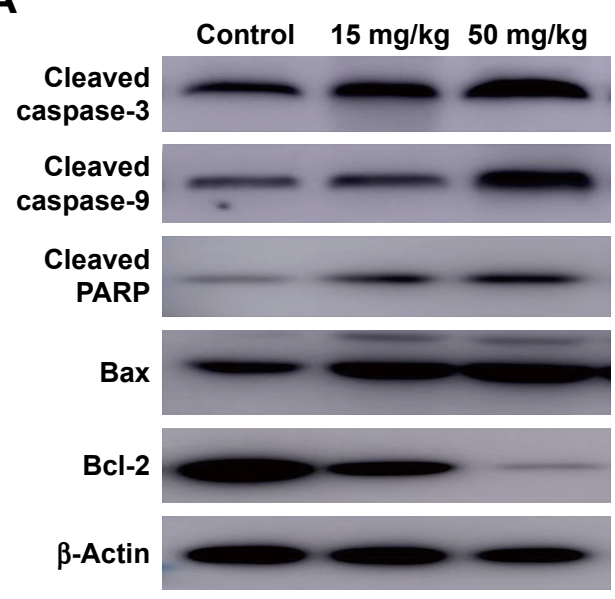

B

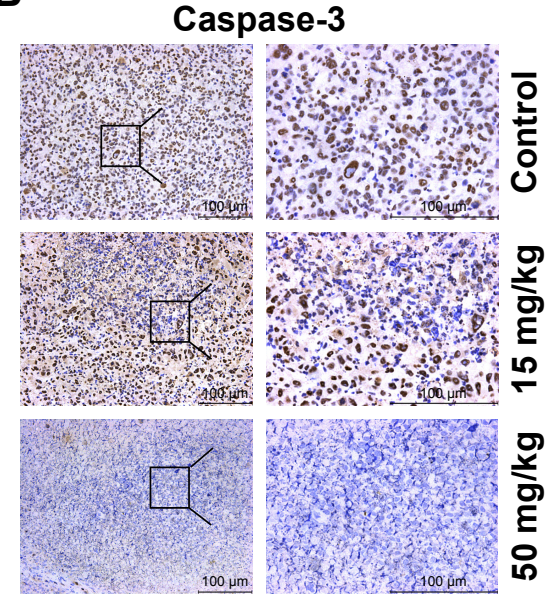

Figure 7 Cordycepin regulates the expression of apoptosis-related proteins in tumor tissue.

Notes: (A) Results of Western blot analysis for the protein level of cleaved caspase-3, cleaved caspase-9, cleaved PARP, Bax, and Bcl-2 from xenograft tumors. $\beta$-Actin was used as a loading control. (B) The expression of caspase-3 (not cleaved) was evaluated by IHC in xenograft tumor.

Abbreviation: IHC, immunohistochemistry. 


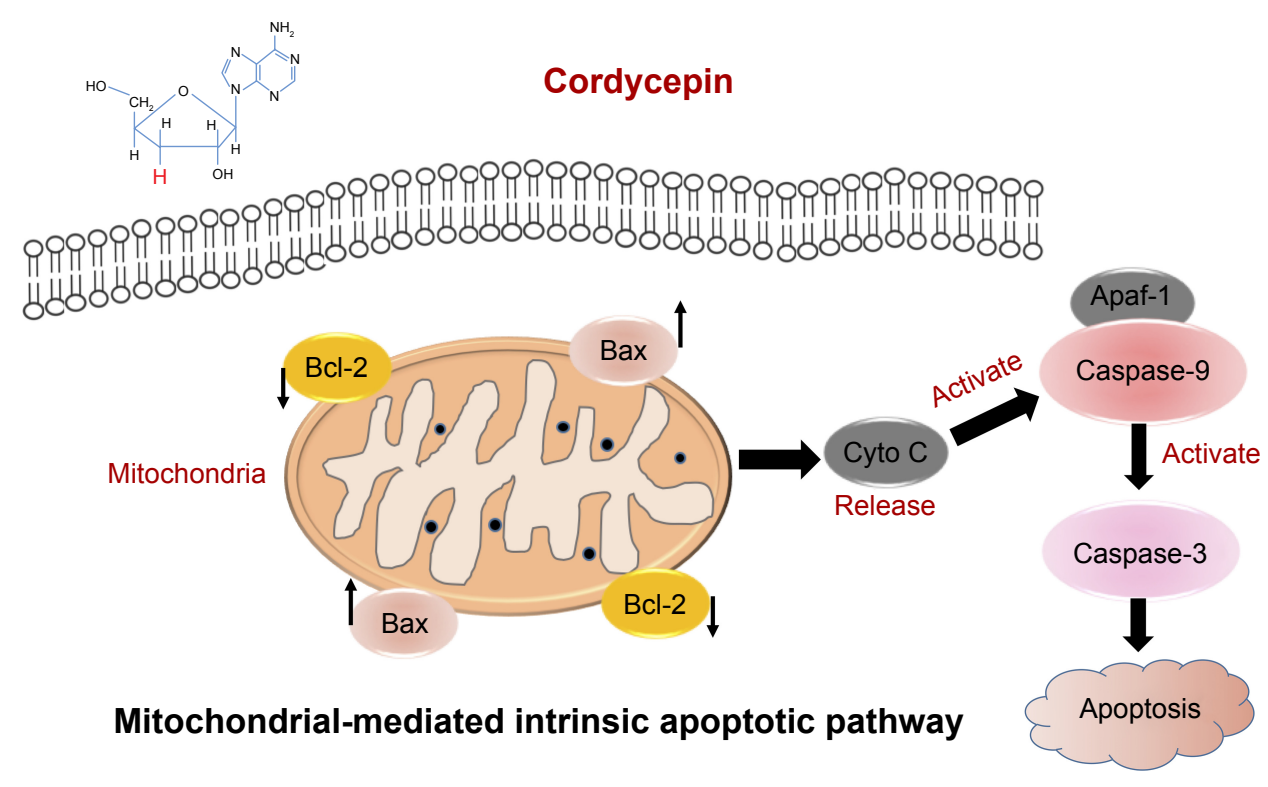

Figure 8 The mitochondrial-mediated intrinsic pathway is involved in cordycepin-induced apoptosis in human pancreatic cancer cells.

the percentage of cells in S-phase was shown to have significantly increased in a dose-dependent manner after cordycepin treatment. In order to reveal the mechanism of cordycepininduced S-phase cell cycle arrest, the expression of cell cycle proteins was investigated. Western blot analysis revealed that the expression levels of cyclin A and CDK-2 proteins, which are 2 key regulators of S-phase, ${ }^{26,27}$ were decreased in cordycepin-treated groups. These data mean that cordycepin blocked cyclin A synthesis, which led to DNA replication failure, thus causing cell cycle arrest at S-phase, therefore leading to tumor growth suppression.

\section{Conclusion}

In summary, the results of the present study revealed that cordycepin possesses potent anti-pancreatic cancer activities owing to its inhibition of cell proliferation, promotion of apoptosis, and induction of cell cycle arrest in vitro, and also by suppression of tumor growth in vivo. These effects correlated with the mitochondrial-mediated intrinsic caspase pathway. Taken together, all these investigations provide sound evidence that cordycepin has potential as a novel anticancer therapy for the treatment of pancreatic cancer. However, further clinical studies are needed to evaluate its clinical value in pancreatic cancer.

\section{Acknowledgment}

This study was supported by the Doctoral Innovation Fund Projects from Shanghai Jiao Tong University School of Medicine (No BXJ201426), the Hangzhou Science and Technology Commission Project (No 20140633B04), the Shanghai Natural Science Foundation (No 17ZR1418500), and Shanghai Pujiang Program (No 17PJD025).

\section{Author contributions}

Wang XA, Chen LT, and Cai WL were responsible for the experimental design. Zhang Y and Yuan RY contributed to the execution of experiments and data statistics. Wang XA, Zhang XX, and Wang $\mathrm{P}$ wrote and revised the manuscript. Ren T, Shao ZY, and Wang HF participated in performing the experiment and in the manuscript mapping and submission. All authors contributed toward data analysis, drafting and critically revising the paper and agree to be accountable for all aspects of the work.

\section{Disclosure}

The authors report no conflicts of interest in this work.

\section{References}

1. Siegel RL, Miller KD, Jemal A. Cancer statistics, 2016. CA Cancer J Clin. 2016;66(1):7-30.

2. Wolfgang CL, Herman JM, Laheru DA, et al. Recent progress in pancreatic cancer. CA Cancer J Clin. 2013;63(5):318-348.

3. Ryan DP, Hong TS, Bardeesy N. Pancreatic adenocarcinoma. $N$ Engl $J$ Med. 2014;371(11):1039-1049.

4. Teague A, Lim KH, Wang-Gillam A. Advanced pancreatic adenocarcinoma: a review of current treatment strategies and developing therapies. Ther Adv Med Oncol. 2015;7(2):68-84.

5. Mian OY, Ram AN, Tuli R, Herman JM. Management options in locally advanced pancreatic cancer. Curr Oncol Rep. 2014;16(6):388.

6. Rossi ML, Rehman AA, Gondi CS. Therapeutic options for the management of pancreatic cancer. World J Gastroenterol. 2014;20(32):11142-11159.

7. Wang XA, Xiang SS, Li HF, et al. Cordycepin induces S phase arrest and apoptosis in human gallbladder cancer cells. Molecules. 2014;19(8): $11350-11365$. 
8. Cunningham KG, Manson W, Spring FS, Hutchinson SA. Cordycepin, a metabolic product isolated from cultures of Cordyceps militaris (Linn.) Link. Nature. 1950;166(4231):949.

9. Chen YC, Chen YH, Pan BS, Chang MM, Huang BM. Functional study of Cordyceps sinensis and cordycepin in male reproduction: a review. J Food Drug Anal. 2017;25(1):197-205.

10. Okur MH, Arslan S, Aydogdu B, et al. Protective effect of cordycepin on experimental testicular ischemia/reperfusion injury in rats. $J$ Invest Surg. 2018;31(1):1-8.

11. Cheng Z, He W, Zhou X, et al. Cordycepin protects against cerebral ischemia/reperfusion injury in vivo and in vitro. Eur J Pharmacol. 2011; 664(1-3):20-28.

12. Ryu E, Son M, Lee M, et al. Cordycepin is a novel chemical suppressor of Epstein-Barr virus replication. Oncoscience. 2014;1(12):866-881.

13. Yang J, Li YZ, Hylemon PB, Zhang LY, Zhou HP. Cordycepin inhibits LPS-induced inflammatory responses by modulating NOD-Like receptor protein 3 inflammasome activation. Biomed Pharmacother. 2017;95:1777-1788.

14. Nakamura K, Konoha K, Yoshikawa N, et al. Effect of cordycepin (3'-deoxyadenosine) on hematogenic lung metastatic model mice. In Vivo. 2005;19(1):137-141.

15. Lee SY, Debnath T, Kim SK, Lim BO. Anti-cancer effect and apoptosis induction of cordycepin through DR3 pathway in the human colonic cancer cell HT-29. Food Chem Toxicol. 2013;60:439-447.

16. Hwang JH, Joo JC, Kim DJ, et al. Cordycepin promotes apoptosis by modulating the ERK-JNK signaling pathway via DUSP5 in renal cancer cells. Am J Cancer Res. 2016;6(8):1758-1771.
17. Shao LW, Huang LH, Yan S, Jin JD, Ren SY. Cordycepin induces apoptosis in human liver cancer HepG2 cells through extrinsic and intrinsic signaling pathways. Oncol Lett. 2016;12(2):995-1000.

18. Su NW, Wu SH, Chi CW, Liu CJ, Tsai TH, Chen YJ. Metronomic cordycepin therapy prolongs survival of oral cancer-bearing mice and inhibits epithelial-mesenchymal transition. Molecules. 2017;22(4): pii: E629.

19. Wang Y, Mo H, Gu J, Chen K, Han Z, Liu Y. Cordycepin induces apoptosis of human acute monocytic leukemia cells via downregulation of the ERK/Akt signaling pathway. Exp Ther Med. 2017;14(4):3067-3073.

20. $\mathrm{Hu} \mathrm{W}$, Kavanagh JJ. Anticancer therapy targeting the apoptotic pathway. Lancet Oncol. 2003;4(12):721-729.

21. Spencer SL, Sorger PK. Measuring and modeling apoptosis in single cells. Cell. 2011;144(6):926-939.

22. Brenner D, Mak TW. Mitochondrial cell death effectors. Curr Opin Cell Biol. 2009;21(6):871-877.

23. Hardwick JM, Soane L. Multiple functions of BCL-2 family proteins. Cold Spring Harb Perspect Biol. 2013;5(2):1-22.

24. Fulda $S$. Therapeutic opportunities based on caspase modulation. Semin Cell Dev Biol. Epub 2017 Dec 15.

25. Rahman MA, Shirai M, Aziz MA, et al. An epistatic effect of apaf-1 and caspase-9 on chlamydial infection. Apoptosis. 2015;20(10): 1271-1280.

26. van den Heuvel S, Harlow E. Distinct roles for cyclin-dependent kinases in cell cycle control. Science. 1993;262(5142):2050-2054.

27. Yam CH, Fung TK, Poon RY. Cyclin A in cell cycle control and cancer. Cell Mol Life Sci. 2002;59(8):1317-1326.
OncoTargets and Therapy

\section{Publish your work in this journal}

OncoTargets and Therapy is an international, peer-reviewed, open access journal focusing on the pathological basis of all cancers, potential targets for therapy and treatment protocols employed to improve the management of cancer patients. The journal also focuses on the impact of management programs and new therapeutic agents and protocols on

\section{Dovepress}

patient perspectives such as quality of life, adherence and satisfaction. The manuscript management system is completely online and includes a very quick and fair peer-review system, which is all easy to use. Visit http://www.dovepress.com/testimonials.php to read real quotes from published authors. 